\title{
Survey on Satisfaction Level of Nursing Students in Internship and Discussion on Strengthening Teaching Management
}

\author{
Xiaona $\operatorname{Jin}^{1, \text { a }}$ \\ ${ }^{1}$ Xi'an International University, Xi'an, Shaanxi, China; Post:710077 \\ ajinxiaonamv@163.com
}

Keywords: Nursing specialty; Clinical internship; Teaching management; Influential factors

\begin{abstract}
Goal] To understand the current satisfaction of nursing students in clinical internship, to analyze its influencing factors, to put forward suggestions on the improvement of the quality of clinical internship and to strengthen the clinical teaching of medical students internship management. [Method] A questionnaire survey of internship satisfaction of 380 nursing students in a university was conducted. The demographic variables of the survey data were analyzed according to sex and academic level, and statistical analysis was made on the influencing factors.[Result] The overall clinical satisfaction of students is good. Among them, the satisfaction rate of teaching ability of clinical teachers is the highest, while the satisfaction rate of school management is the lowest. The satisfaction degree of female intern students in clinical internship is higher than that of male intern students, and that of undergraduates is higher than that of junior college students. [Conclusion] Schools and hospitals should strengthen the clinical internship management in student hospitals, strengthen clinical teachers' awareness of teaching, improve the teaching management system, improve student internship satisfaction, and ensure the smooth progress of student internship.

Nursing is a very practical discipline, and clinical internship is an extremely important practical link in medical education. which is also the most difficult part of teaching management in medical colleges and universities. For nursing students, McRobbie[1] believes that the clinical internship environment can affect students' professional attitudes, nursing knowledge, behavioral skills and ability to solve clinical problems. It is a test of the theoretical knowledge of books and a challenge to make a combination of theory and practice, as well as a key to cultivate the "practical" talent, which is conducive for nursing students who are from classrooms to wards and schools to society. At the same time, McCabe[2] believes that the clinical internship environment can help nursing students to establish good professional roles and enhance their sense of mission and responsibility. Through clinical internship, nursing students get comprehensive exercise in political thought, business technology, medical ethics, style discipline and other aspects, which is conducive to nurturing students' professional ethics and clinical skills training. However, clinical nursing students have characteristics of "long time limit" (one academic year), "long line" (multi-department rotation), "wide distribution" (nursing students in our hospital internship points distribute in more than 30 general hospitals in the province), there are more difficulties in teaching management of college internship. If the management is not proper, the internship results of nursing students will be greatly affected. How to arrange graduation clinical internship rationally, systematically manage graduated clinical internship scientifically and correctly, evaluate graduation clinical internship quality and improve students' clinical internship satisfaction is an important subject worth exploring.
\end{abstract}

\section{Object and Method}

Object. From March to April of 2014, a questionnaire survey was conducted on 2012 undergraduate students and 2013 college graduate students majoring in nursing in our school. There were 195 undergraduate students in 2012 and 185 college graduate students. There were male students while female students 348 . 
Method. Reference to relevant literature and nursing students outline, manual questionnaire was designed. The items and contents of the questionnaire were reviewed and revised by experienced teachers of nursing colleges. A total of 380 questionnaires were distributed and filled in by anonymous form to ensure the authenticity. 368 questionnaires were withdrawn, 11 invalid questionnaires were excluded and 357 valid questionnaires were valid, of which 188 undergraduate students, 169 college graduate students. The recovery rate was $93.95 \%$.

Contents. The questionnaire includes general information (academic level, gender). The satisfaction survey includes a total of five dimensions, which are clinical teaching attitude (6 items), teaching ability of teachers ( 3 items), internship environment ( 6 items), interpersonal relations (3 items) and school management (4 items), which is a total of 22 items. Each item is rated 5 score. All variables use likert5 positive score method, which is that "not satisfied" is 1 score, "not very satisfied" is 2 scores, "generally satisfied" is 3 scores, "quite satisfied" is 4 scores and "satisfied" is 5 scores. The higher the score is, the higher the satisfaction level will be.

Statistical Analysis. SPSS20.0 statistical software was used for comparative analysis of mean and correlation analysis.

\section{Survey Data and Analysis}

From the perspective of gender characteristics, the average score of the factors which make up the satisfaction level, the average score of female is higher than those of males in the average score of the internship satisfaction. T-test $\mathrm{P}<0.05$, gender differences have statistical significant in internship satisfaction. Female internship satisfaction is higher than that of male. See Table 1

Table 1 Clinical internship satisfaction score table of different genders $(x \pm s)$

\begin{tabular}{lccc}
\hline Gender & Score & $\mathrm{t}$ & $\mathrm{p}$ \\
\hline $\mathrm{M}$ & $2.0242 \pm 0.6741$ & -1.001 & 0.024 \\
$\mathrm{~F}$ & $2.6165 \pm 0.8371$ & & \\
\hline
\end{tabular}

From the perspective of education background characteristics, the average score of the factors which make up the satisfaction level, the average score of undergraduate students is higher than those of college graduate students in the average score of the internship satisfaction. T-test $\mathrm{P}<0.05$, education background differences have statistical significant in internship satisfaction. The internship satisfaction of undergraduate students is higher than that of college graduate students. See Table 2

Table 2 Clinical internship satisfaction score table of different education background $(\mathrm{x} \pm \mathrm{s})$

\begin{tabular}{lllll}
\hline Education background & Number & Score & $\mathrm{t}$ & $\mathrm{p}$ \\
\hline Undergraduate students & 188 & $3.7242 \pm 0.1741$ & 2.141 & -0.004 \\
College graduate students & 169 & $2.6430 \pm 0.4221$ & & \\
\hline
\end{tabular}

\section{Analysis of the Individual Factor}

The overall mean satisfaction level is $3.31 \pm 0.28$, which indicates that the satisfaction level to clinical internship of nursing students is middle satisfaction. (See Table 3) 
Table 3 Satisfaction score and scores of each dimension $(n=357)$

\begin{tabular}{cc}
\hline Aspects & Satisfaction score $(\mathrm{x} \pm \mathrm{s})$ \\
\hline Teaching attitude & $2.85 \pm 0.37$ \\
Teaching ability & $3.53 \pm 0.14$ \\
Internship environment & $3.21 \pm 0.25$ \\
Interpersonal relationship & $3.02 \pm 0.31$ \\
College management & $2.78 \pm 0.24$ \\
\hline
\end{tabular}

\section{Discussion}

The results of the internship satisfaction survey of students with different genders and educational background show that undergraduates are more satisfied with clinical internship than college graduate students do and females are more than males do.

Female students are more satisfied with clinical internship than male students do. In our country, the male nurses are extremely scarce, which causes the nursing male students are not accepted clinically by the patients or their families. Many nursing operations will choose female nursing students and male nursing students will have fewer opportunities. Due to the advantages and little quantity, many male nursing students are chosen by emergency department, neurological psychiatrist or operating room when they just began the clinical internship, which reduces the chances of male nursing students to rotate section. At the same time, the turnover rate of male nurses is very high, which also results in that the current clinical departments do not attach importance to the assessment and training of male nursing students. All these factors have caused that male nursing students are less satisfied with clinical internship than female nursing student do.

The satisfaction of undergraduate students is higher than that of college graduate students. Undergraduate students are mostly taking their internship in three-level hospitals. The standardized management, the sound teaching and assessment system promote clinical learning; while college graduate students are taking theirs in hospitals with smaller scale and limited department settings, which is difficult to provide comprehensive learning opportunities for students. Therefore, the satisfaction of undergraduate students is higher than that of college graduate students.

The results of this study show that students 'satisfaction with clinical internship is moderately satisfactory. Among them, students have the highest satisfaction rate of clinical teachers' teaching ability. The lowest score of school management and the second lowest is the clinical teacher's teaching attitude. The long-term working experience in front-line, the clinical teachers have very skilled operating skills, students are satisfied. But because the internship hospitals are not the affiliated ones of our school, the clinical teachers are lack of awareness, so students are not satisfied.

\section{Countermeasures}

Improve the quality of clinical teachers and strengthen the awareness of teaching. To strengthen the teachers' own quality and sense of innovation so that the young teachers can have opportunities to set up lectures, to participate in research projects (subject) group, and to give large-scale health education lectures. To provide developing space for the growth of teachers to improve their exploring ability and to adapt to the update of clinical teaching methods. Second, to change nursing teaching point of view. The traditional teaching mode which only the teacher plays the role in class shall be changed into interactive teaching methods to stimulate student enthusiasm for learning so that innovative potential can be a good play and the abilities of communicate and practice of students can be enhanced $^{[3]}$. Clinical internship is divided into two stages: in the first stage (for 2 to 4 weeks), students specialize in nursing assessment and basic skills training. The designated teachers are the head nurses or nurses with rich experience. teaching; in the second stage, according to the characteristics of the various departments, specific arrangements are made. The task of 
teaching shall be responsible for per person. To implement the "one to one" management approach and to adopt "learning guide" and "question-based teaching methods", so as to stimulate students' interests in learning, to improve their thinking skills, and to strengthen their abilities to analyze and solve problems ${ }^{[4]}$. Teachers shall not only arrange the most simple life care for students in the internship process. Students follow the teachers every day, cleaning, bedding, injecting, infusion, dressing bottles. Hospitals and schools should give clinical teachers policy and treatment to support their enthusiasm, establish a strict and meticulous management system, strict select teachers and carry out pre-job training. In nursing internship, teachers shall teach students accordingly, guide students patiently, encourage students to do more, and coordinate the relationship between students and patients to get the understanding and cooperation of patients, in order to create more opportunities for students to learn. Teacher shall not only take students as a simple workforce. Teacher shall be carried out inspection and supervision. Regular student evaluation shall also be done with reward and punishment.

Clinical internship is an important part of nursing professional teaching plan. Long learning, many subjects and scattered students make teaching management have a certain degree of difficulty. the school should strengthen safety management outside the school and assist the hospital for teaching management ${ }^{[5]}$.Schools should have specialized institutions and personnel to participate in the hospital management of nursing students. Regular visits to the internship hospital shall be done to understand the internship and living conditions and timely feedback to the hospital the existing management issues, to ensure the smooth progress of clinical internship.

Strengthen the training of clinical teachers and improve the level of teaching. As there is a gap between the academic level and teaching level of clinical teachers with the rapid development of nursing education. To strengthen the clinical teacher training is the effective measure to quickly improve the overall level of teaching ${ }^{[6]}$.Hospitals shall collaborate with schools to provide various training and learning environment for teaching teachers through various means and channels. Establish the necessary incentive mechanisms to improve the quality of clinical teaching.

According to the teaching objects, choose different teaching methods. Based on nursing students with different levels, adopt different training objectives, which should not be the same. Different teaching methods should be chosen so that students can participate more in nursing internship ${ }^{[7]}$. To improve the clinical teaching effectiveness and teaching quality. First, improve the teaching management system, internship management team composed by directors of nursing department and nurses of nurse's ward of the hospital can develop relevant internship strategies and coordination mechanisms, regularly inspect and improve he evaluation of internship comprehensive ability. Semi-quantitative assessment methods, including the workload, ability and operating skills and theoretical test scores, can be used to objectively and truly reflect the overall level of students ${ }^{[8]}$.

Enhance nursing students' subjective initiative, learning interest and learning motivation. Strengthen pre-service training, improve students' ability of coping with problems, help them to familiarize themselves with the environment as soon as possible and eliminate psychological pressure. Teachers should be responsible for introducing departments' environment, layout, diseases type and commonly used nursing techniques, to make nursing students can be familiar with the environment as soon as possible[9].Fully mobilize the enthusiasm of interns, guide them to communicate with patients and obtain the trust of patients and their families, which is the way to improve the clinical internship. Teachers should create opportunities for students as many as possible to take the initiative to communicate with patients, learn caring for patients, access to patients' trust. Encourage, care, help and guide students in their work ${ }^{[10]}$. Consciously train students' ability to solve problems, to think and to contact theory. Develop their ability to analyze problems, strengthen their communication skills in nurse-patient relationship. Development their psychological care and health education. Make students be familiar with the environment and the object of care, reduce fear and tension of nursing students. 


\section{References}

[1] McRobbie CJ. Fraser BJ. Associations between student out comes and Psychosocial science environment.Journal of Education.Research.1993(87): 78-85.

[2] McCabe B.The improvement of instruction in the clinical area: a challenge waiting to be met Journal of Nursing Education,1985,24(16): 255-257.

[3] Dongjun Wang, Yufang Zhao and Zhong He. Factors Affecting the Quality of Nursing Clinical Teaching [J]. Journal of Nursing Management, 2006 (3): 7-9.

[4] Fangrong Feng, Jinmei Li. Experience of Cultivating Communication Ability of Nursing Students [J] Journal of Nursing Management, 2005 (9): 18-19.

[5] Jianshan Huo, Miaoxia Chen and Ou Zhaolan. Shortcomings and Countermeasures of Nursing Practice Teaching [J]. Modern Clinical Nursing, 2006 (6): 19-21.

[6] Xiaoqin Ma, Xuya Lu and Wang Guojian. Investigation and Analysis of Existing Problems in Clinical Nursing Teachers [J]. Zhonghua Nursing, 2007,4 (2): 81-82

[7] Zhang'an Wang, Bin Wu and Qiuping Ma. A Qualitative Study on Undergraduate Nursing Students' Expectations for Teachers [J] Journal of Nursing Administration, 2013,27 (7): 2090-2092.

[8] Hongmei Zhao and Shouhua Zheng. Survey on the Needs to Clinical Teachers of Nursing Students with Different Education Background [J]. Journal of Nursing, 2013,28 (5): 63-64.

[9] Liujuan Yang, Xiaolian Jiang and Xiaoping Li. A Comprehensive Qualitative Study on Undergraduate Nursing Students' Expectations for Clinical Teachers [J]. West China Medicine, 2012,27 (2): 288-291.

[10] Yan Ren and Xiaoying Hu. Research on Learning Motivation and Relationship between Teachers and Students in Nursing Interns [J]. Journal of Nursing Science, 2012,47 (6): 521-525. 